\title{
Teatro União e Olho Vivo: uma perspectiva de longo prazo de Teatro para Comunidades ${ }^{1}$.
}

\author{
Márcia Pompeo Nogueira ${ }^{2}$ e Maireli Dittrich ${ }^{3}$
}

Palavras-chave Teatro para comunidades; teatro popular; TUOV; sustentabilidade.

Resumo: Este artigo traz em linhas gerais a história do Grupo Teatro Popular União e Olho Vivo, sua fundação e, de maneira breve, fatos do inicio de sua história. Propõe ainda mostrar as premissas do grupo, sua opção de fazer teatral e como se dá a realização de suas peças. Este fator direciona o estudo para os anos atuais onde se busca, compreender os pilares de sustentabilidade do grupo.

\section{Introdução}

O Banco de Dados para o desenvolvimento de teatro comunidade foi criado na intenção de reunir dados sobre grupos de teatro na comunidade do país, a partir do preenchimento de um formulário on line. Estando em prática há dois anos, infelizmente, os resultados almejados estão longe de ser atingidos. Por mais que sejam enviados e-mails ou feitos contatos de diferentes formas, o preenchimento continua bastante limitado.

Tentando manter o objetivo do projeto de coletar dados sobre a prática de teatro na comunidade, optamos por pesquisar grupos específicos, de forma a redigir artigos que possam ser disponibilizados no site do Banco de Dados.

A escolha do grupo foco deste artigo foi motivada pelo trabalho de longo prazo na área do Teatro Comunitário: os grupos de teatro comunitário têm, geralmente, pequena duração, sendo raros os que conseguem estar ativos por mais tempo. Um destes grupos é o Teatro Popular União e Olho Vivo (TUOV) que está ativo há 41 anos na cidade de São Paulo.

\footnotetext{
${ }^{1}$ Grupo de Pesquisa: "Banco de Dados para o Desenvolvimento de Teatro em Comunidade" - CEART / UDESC ${ }^{2}$ Márcia Pompeo Nogueira Professora do Departamento de Artes Cênicas do CEART / UDESC.

${ }^{3}$ Acadêmica de Artes Cênicas CEART / UDESC, bolsista de Iniciação Cientifica PIBIC.
} 
O TUOV atua no que chamamos de "Teatro para Comunidades" (Nogueira, não publicado). Sua prática tem motivado a criação de diferentes grupos de "Teatro com a Comunidade", isto é, grupos de pessoas de comunidades que se motivaram a criar seus trabalhos teatrais a partir do apoio do TUOV.

Mas, o que faz com que um grupo como o TUOV esteja vivo há tanto tempo? O que sustenta um grupo como este e o faz prosseguir e estar presente em vários festivais nacionais e internacionais?

Por estas perguntas fez-se uma visita à sede do grupo nos dias 14 e 15 de abril de 2007. Nossa intenção era conviver com o grupo e conhecer como fazem e por que fazem teatro. Neste sentido, o presente artigo se fundamenta em livros escritos pelo grupo e sobre o grupo, em sites da internet e da observação de um encontro de trabalho deste grupo.

\section{A Formação do TUOV}

TUOV é apelido do Grupo “Teatro Popular União e Olho Vivo”. Criado em 1966, está há 41 anos na luta por um teatro popular de qualidade, expondo seus pensamentos e ideais.

Criado por estudantes, em 1965 levava o nome de "Teatro do Onze". Sua sede era o Centro Acadêmico XI de Agosto, do curso de direito do Largo São Francisco, da Universidade de São Paulo, USP. Seus precursores foram, entre outros, Silnei Siqueira, Neriney Moreira e César Vieira (pseudônimo do advogado Idibal Pivetta), sendo este último seu principal líder.

Duas peças de César Vieira foram precursoras do TUOV: "O Evangelho segundo Zebedeu", foi apresentada pelo Teatro do Onze e dirigida por Silnei Siqueira e "Corinthians, meu amor", representada pelo Teatro Casarão, grupo atuante da época que tinha sede em um casarão da Rua Brigadeiro Luiz Antonio. Após essas montagens, componentes do Teatro do XI se uniram a alguns remanescentes do Grupo Casarão para discutir idéias de teatro popular, algumas questões referentes ao público que gostariam de atingir e a circulação em bairros periféricos a preços acessíveis. (GARCIA, 1990, p.132). A primeira peça deste novo grupo foi “Rei Momo", em 1973.

Neste período o grupo se desvincula do Centro Acadêmico e passa a se denominar “Teatro Popular União Olho Vivo”. O nome é originário do último espetáculo, Rei Momo, e se refere ao "Grêmio Recreativo Escola de Samba União e Olho Vivo", que figurava na peça. 


\section{A Escolha do Público Alvo}

As primeiras convicções firmadas pelo grupo foram as de que seu teatro, para chegar da maneira que queriam, no público que queriam, deveria ser apresentado próximo àquelas pessoas, em seu próprio território e com preço compatível ao poder aquisitivo de sua platéia.

Dessa maneira, discutiram como deveriam ser as peças, seus contextos e temas. Para "Rei Momo" escolheram a forma de desfile de escola de samba. A "ópera-samba" conta a História do Brasil em forma de revista durante a eleição do rei do carnaval em um baile no Teatro Municipal do Rio de Janeiro. (CACCIAGLIA, 1986, p.143)

Chegou-se a conclusão de que um espetáculo com as intenções a que o grupo se propunha deveria ter ingredientes populares e trazer consigo uma mensagem de defesa dos interesses dos oprimidos (VIEIRA, 1980,p. 39).

Para essa apresentação foi retomado o terreno do Teatro do XI. A lona foi levantada pelos integrantes do grupo e as novas instalações foram adquiridas por doações e empréstimos.

As apresentações ${ }^{4}$ foram destinadas a classe média, com preços inferiores aos dos teatros convencionais. Logo o grupo começou a receber convites para se apresentar em comunidades.

Uma das ideologias do TUOV começou a ser praticada. Passou-se a vender espetáculos para colégios e centros acadêmicos e, com esse dinheiro, cobriam-se as despesas das apresentações na periferia. Essa é chamada “Tática Robin Hood”, ainda executada.

Como os integrantes do grupo, além de fazer teatro, trabalhavam fora, o grupo decidiu que, para fazer uma apresentação era preciso saber o motivo pelo qual essa população a havia solicitado: para tal engajavam pessoas do bairro na panfletagem e divulgação.

Mas como tirar o público de casa para assistir a peça? A solução foi inspirada no carnaval. O ritmo de samba embalou apresentações: em forma de "desfile", os moradores foram convidados a prestigiar a peça, na Zona Norte de São Paulo.

\section{As escolhas que norteiam a proposta estética do grupo}

${ }^{4}$ A peça estreou em 06/ 11/ 1972,

DAPesquisa, Florianópolis, v.2, n.4, p. 090-097, 2007. 
A partir da prática, outras questões surgiram: como levar o material de cenário e figurino para o espaço sendo que, para todos os 50 membros, apenas 03 ou 04 possuíam carro? Como trabalhar a iluminação para locais que não tinham capacidade?

Foi a partir destas mesmas apresentações que as dúvidas foram sanadas. Passou-se a pensar em cenários práticos e simples: O TUOV utiliza desde então cubos pretos de vários tamanhos como cenário, que são montados a partir da necessidade da cena (um barco, um trono, etc.).

Logo em seu início o grupo já conseguia colocar em prática suas intenções. Mais que fazedor de teatro, o TUOV se mostrava transmissor de idéias.

Essa fluência de comunicação entre o grupo e sua platéia fez com que alegassem que as peças do TUOV eram manifestações políticas. Por três meses, durante o ano de 1973, ficaram sem pratica. Parte do material fora apreendido e elementos do grupo foram detidos. (VIEIRA, 1997 p. 43)

Ao retorno das atividades vieram os primeiros convites internacionais. O grupo aceitou viajar: Polônia, França, Itália e Iugoslávia. A imprensa internacional deu grande divulgação ao grupo.

De volta ao Brasil, o TUOV continuou com suas apresentações, suas táticas e seus pensamentos. Integrantes saíram, outros entraram. Peças novas foram montadas sempre com o mesmo enfoque: "Teatro popular [que] será escrito e montado por elementos populares, com tema em defesa de seus próprios interesses, apresentado num local popular a preços accessíveis ao poder aquisitivo da população do lugar.” (VIEIRA, 1980, p.54).

No ano de 2006 foram comemorados 40 anos de grupo: desde "O Evangelho segundo Zebedeu” até “João Candido do Brasil”, última peça montada pelo grupo.

\section{Princípios que norteiam o TUOV}

O TUOV é o grupo popular mais antigo do Brasil. Como o grupo sobreviveu? O que o faz existir há tanto tempo? Mesmo a ditadura não foi capaz de desintegrá-lo. Sem dúvida, é uma trajetória surpreendente! Talvez o que tenha auxiliado nessa longevidade sejam as regras criadas pelo grupo em seu inicio: 
São 20 premissas que regem o grupo, subdivididas em: Grupo, Temas, Espetáculo, Apresentações, Relação do grupo com o Bairro, Relação do grupo com a realidade social e Relação com outros grupos, originárias dos três princípios básicos:

1 - Estrutura semelhante à de um clube de futebol: formado por pessoas humildes que pratiquem regularmente o teatro durante o final de semana e que discutam os problemas pessoais, do grupo e da comunidade;

2 - Prática semelhante à da capoeira: para atingir aquilo ou aqueles, devem usar de indiretas cênicas para que não sejam julgados ou caçados;

3 - Preços acessíveis às periferias e a seus moradores.

Estas "regras" criadas em 1974 vigoram até hoje, sofrendo as alterações necessárias com a época em que estão. (GARCIA, 1990 p.133)

\section{A Opção pelo Social}

As peças montadas são de cunho social. Mostram algum fator histórico contado, mas, muitas vezes, de uma maneira mais suave. São relacionados à cultura popular e a favor das necessidades e aspirações populares.

Característica deste teatro popular social, a proposta do TUOV "descarta o teatro enquanto mero entretenimento e determina um compromisso de solidariedade do produtor com os problemas e necessidade das populações periféricas (...)" (GARCIA, 1990, p.124). O teatro do TUOV quer trazer algo do povo para o povo.

Mesmo que comandado por uma pessoa de classe média, (o TUOV em seus 41 anos é dirigido por César Vieira), comumente os integrantes do grupo são de baixa renda. Mas qualquer pessoa que sentir-se atraída pelo estilo do grupo, suas peças e pensamentos, pode fazer parte do TUOV, passando por um período de adaptação e aceitando a proposta do grupo:

(...) [O] TUOV entende que seu trabalho deve estar a serviço dos movimentos populares no processo de mobilização e organização de suas reivindicações (...) (GARCIA, 1990, p. 127). 
Após uma apresentação é feito um debate com o público. Mais do que contar por que estão ali, o TUOV quer ouvir sugestões acerca da peça, das falas, das personagens, dos figurinos e do cenário. Se surgir algum comentário relevante, pode-se alterar a peça, de acordo com comentário do público e com o olhar do grupo para aquela criação.

\section{O Processo Criativo e a base na dramaturgia}

O processo de escolha de um tema não tem período para acontecer. Pode demorar meses ou anos, desde que a peça seja de acordo com os ideais do grupo. Cada integrante deve trazer de três a cinco sugestões de fatos históricos sociais, estudar e argumentar a favor da montagem desse tema. Definido este, dados e fontes históricas são trazidos para o grupo e a história vai sendo remontada a partir da visão de todos.

É feita a coleta de informações para subsidiar a construção da dramaturgia. Cada integrante pode escolher este ou aquele fato ou personagem para que seja incluído na cena. Ao notarem que já possuem materiais suficientes de pesquisa, a comissão responsável começa a escrever o texto.

Para cada montagem são montados grupos específicos - comissões - para cuidar do figurino, do cenário, da iluminação, das músicas e da dramaturgia, sempre liderada por alguém especialista. Já tendo algo pronto fazem uma demonstração para o coletivo que opina, acatando ou propondo alterações.

Durante o processo de criação de arte vão acontecendo os ensaios. A escolha dos personagens é feita de acordo com a desenvoltura de cada um. A vontade de fazer uma personagem pode ser acatada, dependendo da aceitação do coletivo e do diretor.

A base da criação vem da dramaturgia. Para cada nova peça todos se envolvem, não tendo motivos para se sentirem isolados ou excluídos. Todos devem dar sua contribuição para o bem do grupo. Essa característica, conforme Garcia, foge dos padrões do teatro comercial e profissional (GARCIA, 1990 P.133).

\section{A Busca do Acordo de Grupo}

Não é difícil de imaginar que um grupo grande como o TUOV (hoje com cerca de 20 integrantes) tenha desavenças em suas relações pessoais. Para essas o grupo criou a "comissão 
de anteparo". Quando existe discordância entre os participantes, esta comissão, composta pelos integrantes mais experientes, conversa, buscando resolver a questão.

Para aqueles que conhecem o grupo, é muito atraente a forma como os assuntos gerais são resolvidos: todos devem expor sua opinião. Um por um, sem censura nem crítica, vai expondo sua sugestão.

\section{O Contato com outros grupos de Teatro na Comunidade}

O grupo começou um projeto de disseminação do teatro no bairro do Jaraguá, também em São Paulo. Apadrinharam um grupo de pessoas e cederam, a estes, uma de suas peças, no caso, "Barbosinha Futibó Crubi". O grupo, "Fonteatro" existiu por dois anos. Infelizmente não germinou. Hoje integrantes do "Fonteatro Jaraguá" estudam a possibilidade de ingressar no TUOV.

O TUOV possui uma sede própria no bairro do Bom Retiro, São Paulo. Cada final de semana uma dupla é responsável pela limpeza, organização, manutenção, etc.

Na sede, o grupo demonstra suas preocupações com o social: no galpão de madeira, que servia de deposito, habita há cerca de oito anos o Sr. Joaquim ${ }^{5}$, enfermeiro e ex-morador de rua; um dos camarins foi transformado em "quarto" e é habitado por um dos integrantes, estudante e sem condições financeiras de pagar aluguel.

A sede também é emprestada para apresentações e recebe o encontro de artistas e teatro de rua da cidade de São Paulo.

\section{A sustentabilidade do grupo}

O que faz com que o grupo esteja firme há tanto tempo, sobrevivendo a mudança de elenco, problemas políticos, culturais, sociais e financeiros?

Não se podem tirar conclusões sobre o grupo sem conhecê-lo profundamente. Ao analisarmos as perspectivas do TUOV, não é difícil de considerar sua sustentabilidade como utópica: os integrantes são oriundos das camadas populares da população, trabalham ou estudam durante a semana e praticam o teatro nos sábados e domingos. Não recebem muitos cachês ou 
salário. Mas, por mais difíceis que sejam as situações pessoais ou grupais, estão lá, fiéis, trabalhando.

Analisando a trajetória do grupo, identifico fatores que auxiliam na permanência do grupo há tanto tempo:

- A conversa no ambiente interno, onde todos têm direito e dever de manifestação, é exemplar e faz com que o grupo seja verdadeiro em suas relações e opiniões;

- As comissões, que se alteram de acordo com o projeto, permitem que todos vivenciem algo novo e aprendam um pouco de tudo, trazendo sempre à tona o interesse pelo desconhecido;

- Ter um responsável nestes 41 anos na busca de um teatro popular de qualidade;

- O amor que os integrantes sentem pelo grupo, pelo teatro, pelas questões sociais que abarcam e pela mensagem que transmitem (o mais poético e verdadeiro pilar).

Esses pilares que edificam o TUOV mostraram-se efetivos já que o grupo conseguiu se manter por todos esses anos. Será que outros grupos de teatro comunitário poderão se beneficiar deste conhecimento? Esperamos que este artigo possa contribuir para divulgar ainda mais a prática do TUOV, de forma a que sua história sirva de inspiração para outros grupos comprometidos com a democratização do acesso ao teatro.

\section{Referências:}

CACCIAGLIA, Mario. Pequena historia do Teatro no Brasil. São Paulo: Edusp, 1986.

GARCIA, Silvana. Teatro da Militância. São Paulo: Perspectiva, 1990.

NOGUEIRA, Márcia Pompeo. “Teatro na Comunidade”. Artigo não publicado.

VIEIRA, César. Em busca de um teatro popular. São Paulo: Unesco, 1977. http://paginas.terra.com.br/arte/tuov/index.htm

http://www.teatropopularolhovivo.hpg.ig.com.br/index 1.htm 